\title{
Understanding the adoption of smartphone apps in dairy herd management
}

\author{
Marius Michels, ${ }^{*}$ Vanessa Bonke, and Oliver Musshoff \\ Department of Agricultural Economics and Rural Development, Georg-August-University Göttingen, Platz der Göttinger Sieben 5 , \\ D-37073 Göttingen, Germany
}

\section{ABSTRACT}

The number of decision support tools available to farmers, including dairy herd management smartphone apps, has been steadily increasing. The existing literature does not cover topics concerning the adoption and use of herd management smartphone apps or which specific functions of such apps are perceived as most useful by dairy farmers. It is unclear whether technology adoption can only be explained by economic reasoning, because the beliefs about a technology also play a role in decision-making. Therefore, this study seeks to determine whether an extended technology acceptance model can explain adoption and use of herd management smartphone apps. Results about the adoption and use of dairy herd management smartphone apps are derived from an online survey conducted in 2018 with 280 German dairy farmers. To model farmers' frequency of use of herd management smartphone apps, we applied partial least squares structural equation modeling and an ordered logit model. Our results show that $93 \%$ of the dairy farmers in our sample use a smartphone and $61 \%$ already use a herd management smartphone app. Daily use is reported by $38 \%$ of the adopters. Dairy farmers rated functions related to the observation of animal health, reproduction management, and data gathering as most useful, which should be in focus by developers and providers for future development. The key attitudinal components of the technology acceptance model, namely perceived ease of use and perceived usefulness, both positively influence the intention to use such apps. This ultimately has a positive effect on the actual usage behavior. Besides other factors, dairy farmers' education and knowledge of herd management smartphone apps have a positive effect on perceived ease of use. Our model explains $33 \%$ of the variance in the actual usage behavior related to herd management smartphone apps. Because perceived ease of use and perceived usefulness positively influence the intention to use such apps and

Received February 14, 2019.

Accepted May 21, 2019.

*Corresponding author: marius.michels@agr.uni-goettingen.de ultimately the actual usage behavior, developers and providers should highlight the benefits of using herd management smartphone apps and also keep the interface of the apps as simple as possible.

Key words: herd management smartphone app, German dairy farmer, partial least squares structural equation modeling, technology acceptance model

\section{INTRODUCTION}

Herd management practices largely affect the productivity of dairy farms (Borchers, 2015). As dairy herd sizes increase, herd management becomes increasingly difficult and time consuming for a dairy farmer (Gargiulo et al., 2018). Insufficient herd management can result in reduced animal welfare and health, which can lower cow performance and harm the economic status of the dairy farmer (Calsamiglia et al., 2018). Furthermore, record keeping and evaluation at the cow level are considered to be essential for monitoring herd performance and making effective herd management adjustments if necessary (Barragan et al., 2016). However, shifting from management of the herd as a whole to management of the individual cows within the herd is contingent on the collection and evaluation of data in (near) real time (Debauche et al., 2018).

Recent developments in smartphone technology, access to mobile internet, and cloud services have led to an increase in the number of smartphone apps supporting farmers' decision-making (Rose et al., 2016). Smartphones and associated apps can be used in connection with other precision agricultural technologies or independently. Furthermore, smartphone apps fit well into the working routine of farmers due to their mobile character.

The use of smartphone apps might also enhance a dairy farmers' decision-making and the adoption and use of data-driven precision dairy technologies. For instance, herd management smartphone apps, as a form of decision support tool (DST), can be used to enter and assess cow individual data (Abdelsayed, 2017). Monitoring cows via sensor technology and smartphone apps can provide essential information on their health 
or reproductive status as well as their feeding, lying, and moving behavior in real time (Debauche et al., 2018). Sensing technology and real-time monitoring combined with smartphones and associated apps enable a dairy farmer to react faster and allow for improved decision-making in livestock management (Kamilaris and Pitsillides, 2016). The combination of smartphone apps with stationary management systems and precision dairy technologies can additionally allow a dairy farmer to review and enter individual animal data from anywhere at any time (Herd, 2014).

Although the adoption of various precision dairy technologies by dairy farmers to improve production on dairy farms has been studied (e.g., Borchers and Bewley, 2015; Gargiulo et al., 2018), information about the implementation of smartphone-based DST in herd management is currently very limited because most studies focus on the technological side (e.g., Herd, 2014; Kamilaris and Pitsillides, 2016; Debauche et al., 2018). It is unclear whether technology adoption can only be explained by economic reasoning, as beliefs about a technology also play a role in decision-making. Therefore, this study sought to determine whether an extended technology acceptance model (TAM) could explain adoption and use of herd management smartphone apps. Whereas the original version of the TAM focuses on the decision to adopt a technology or not (Davis, 1989), we included the use frequency of smartphone herd management apps as an endogenous variable to further differentiate adoption behavior.

Without assessing the potential usefulness or value that a DST has for a farmer, adoption and use will remain low (Evans et al., 2017). Therefore, we also wanted to identify which herd management smartphone app functions dairy farmers perceive as useful. This is the first study to focus on adoption and use of smartphone herd management apps in dairy farming and also covers which functions are perceived as useful by the dairy farmers. Motives and obstacles to adoption, usage behavior, and the perceived usefulness of technology functions from a farmer's point of view are of high interest for developers and providers (Glenna et al., 2011), educators who develop educational programs (Thompson et al., 2018), and researchers in precision dairy technologies.

\section{MATERIALS AND METHODS}

\section{Theoretical Framework}

Innovation adoption is regarded as inevitable if the advantage is clear and adoption is rather effortless (McDonald et al., 2016). However, these conditions almost never hold true for technological innovations.
In particular, demonstrating the economic value of precision agriculture technologies comes with difficulties (Mintert et al., 2015). It has been shown that decisions on innovation adoption are not based only on proposed economic advantages (e.g., McDonald et al., 2016). Specifically, Vanclay (2004) as well as Mills et al. (2017) noted that farming is not only perceived as an income-generating activity but that farmers' decisionmaking is affected by their attitudes and beliefs toward the adoption of a technology or behavior (e.g., Kuehne et al., 2017). The TAM is based on the theory of reasoned action, which is a psychological model proposing that an individual's attitude toward an action plays an important role in their behavior (Fishbein and Ajzen, 1975). The TAM is the most widely applied model for technology adoption (Verma and Sinha, 2018) and has also been used in the dairy sector (e.g., Schaak and Mußhoff, 2018). Our proposed TAM and its extensions for herd management smartphone app adoption are explained in the following.

According to the TAM, an individual's behavioral intention to use (ITU) a technology is determined by the perceived ease of use (PEOU) and perceived usefulness (PU) of this technology (Davis, 1989). PEOU is defined by Davis (1989) as the degree to which an individual perceives using a technology as easy or effortless. The PEOU also affects PU because, ceteris paribus, the easier a technology is to use for an individual, the higher the perceived usefulness by that same individual (Davis, 1989). Borchers and Bewley (2015) show that dairy farmers who do not know how to use precision dairy farming technologies are less likely to be adopters. Thus, if a dairy farmer thinks implementing and using a herd management smartphone app is easy, he or she has a higher intention to use such an app. Moreover, if a dairy farmer perceives handling a herd management smartphone app as difficult or learning to use it as very time consuming, he or she may come to the conclusion that such an app is not useful. The PU refers to the extent to which an individual perceives that a technology enhances his or her job performance (Davis, 1989). A DST should provide information that is useful for the farmer's work, because otherwise, adoption will not occur (Rose et al., 2016; Bonke et al., 2018). To summarize, if a dairy farmer perceives herd management smartphone apps as useful to obtain information to make better production decisions or to observe animal behavior, he or she is more likely to have a higher intention to use herd management smartphone apps. The following hypotheses represent the described relationships.

- H1a - The PEOU has a positive effect on the PU of herd management smartphone apps. 
- H1b - The PEOU has a positive effect on the ITU herd management smartphone apps.

- H2 - The PU has a positive effect on the ITU herd management smartphone apps.

Besides the beliefs about a technology, which are captured by the classical TAM framework, farmers as well as farm characteristics play a crucial role for technology adoption. Therefore, our TAM is extended by several variables that are hypothesized to influence the key constructs PU and PEOU. In the agricultural context, farm size plays an essential role in technology adoption. With respect to dairy technology adoption, Läpple et al. (2015) and Gargiulo et al. (2018) provide evidence that larger herd sizes increase the likelihood of adoption of new technologies. Benefits from data collection and evaluation for individual animals are higher for larger herds, because individual animal management becomes more challenging with increasing herd size (Gargiulo et al., 2018). This could be made easier by the use of smartphone apps (Herd, 2014; Debauche et al., 2018). Thus, it is plausible that dairy farmers with larger herd sizes have a higher PU of herd management smartphone apps. Hence, we hypothesize the following.

- H3-Managing larger herd sizes has a positive effect on the PU of herd management smartphone apps.

McDonald et al. (2016) show that milk yield and technology adoption are positively related. Their findings suggest that producers with better performing herds try new technologies to maintain their production level or to achieve even higher production gains. Hence, it is also plausible that a dairy farmer with a high milk yield may want to maintain or increase his or her high production level and thus perceives the information and functions provided by herd management smartphone apps as more useful. We therefore hypothesize the following.

- H4-Achieving high milk yields has a positive effect on the PU of herd management smartphone apps.

One of the major influences on technology adoption discussed in the literature is the age of the farmer (Läpple et al., 2015). Tamirat et al. (2018) suggest that older farmers have a lower demand for information or management of information due to their higher farming experience. With respect to our research, this implies that an older dairy farmer may benefit less from the in- formation provided by using herd management smartphone apps because he feels experienced enough to not be dependent on herd management smartphone apps. A dairy farmer may have already established other sources of information or DST and therefore does not perceive herd management smartphone apps as useful. Moreover, skills to work with mobile devices are likely to be better among younger adults (Gerpott et al., 2013), which holds also true with respect to younger farmers and their use of computers and smartphones (Rose et al., 2016). Hence, an older dairy farmer who is less experienced with smartphones or digital technologies may perceive herd management smartphone apps as difficult instruments to use and therefore rate their usefulness lower. All in all, this is represented by the following hypotheses.

- H5a-Increasing age has a negative effect on the PU of herd management smartphone apps.

- H5b-Increasing age has a negative effect on the PEOU of herd management smartphone apps.

For DST in general, Rose et al. (2016) reason that farmers who are used to computers and smartphones will be more likely to use new software and apps, as these may not be as difficult to adopt considering their current use of technology. In line with that, Bonke et al. (2018) show that farmers who are aware of the existence of crop protection apps are more likely to be willing to pay for these apps. Hence, it is plausible that a dairy farmer who is aware of and already informed about herd management smartphone apps perceives the use of such apps as easier than dairy farmers who have no knowledge about such apps, as expressed by the following hypothesis.

- H6 - Knowledge of herd management smartphone apps has a positive effect on the PEOU of herd management smartphone apps.

Education is considered to be one of the most important socioeconomic factors in information technology adoption because education improves an individual's ability to understand and decode information (Rose et al., 2016). Effective use of herd management smartphone apps may require substantial learning. Carrer et al. (2017) argue that for farmers with increasing levels of education, the ability to learn how to use a computer and to make value of the produced information also increases. Therefore, it can be concluded that a higher level of education eases the adoption and use of herd management smartphone apps for dairy farmers. This is displayed by the following hypothesis. 
- H7-Higher education has a positive effect on the PEOU of herd management smartphone apps.

The target construct of the TAM is the actual usage behavior, which is influenced by the intention to use a technology. In contrast to Davis (1989), the actual usage behavior is not modeled as a dummy variable but as an ordinal variable, measuring the frequency of dairy herd management smartphone app use. The following hypothesis will therefore be tested.

- H8 - The ITU has a positive effect on the frequency of using herd management smartphone apps.

Grazing behavior is an important indicator for cow health and grass utilization (Werner et al., 2018), which in turn are considered to be the major determinants for the efficiency of pasture systems (Shalloo et al., 2018). Shalloo et al. (2018) described connectivity challenges as one of the obstacles to implementing sensor technologies in grazing systems. Although sensors on the cow can collect data as the cow is feeding and moving around in indoor systems, missing wireless connections at remote pastures can inhibit on-time data transfer to the smartphone app. Data will be only synchronized, for instance, when the cow enters the barn. Because the data are updated less frequently, we assume that farmers who have outdoor grazing practices in place do not use apps as frequently as farmers who do not have grazing herds. Hence, the following hypothesis will be tested.

- H9-Pasture access has a negative effect on the frequency of using herd management smartphone apps.

\section{Data Collection}

An online survey addressed to German dairy farmers was conducted from March to May 2018. Dairy farmers were found via social media channels and the Alliance of German Dairy Farmers. Ninety-five percent of German farmers used the internet in 2016 (Kleffmann Group, 2016), justifying an online survey as a useful method to reach a large number of farmers. The descriptive statistics were also compared with the German average (Kleffmann Group, 2016; DBV, 2018; Federal Office for Agriculture and Food, 2019)

The survey was structured as follows. First, dairy farmers were requested to give their evaluation of 10 randomized statements that are the basis for the developed TAM for dairy herd management apps (Table 1). We used 5 -point Likert scales $(1=$ fully disagree; $5=$ fully agree) for the statements of the TAM. The wording of the statements was based on the work of Davis (1989) and Venkatesh and Davis (2000) but adapted to our field of research. Second, dairy farmers were asked to evaluate the usefulness of several herd management app functions (functions with respect to reproduction management, animal health, data gathering, milking control, feed management) on equally spaced 5 -point Likert scales ( $1=$ not useful at all; $5=$ very useful). (Functions were evaluated and summarized by analyzing available apps in the Google PlayStore and iOS Store by using the key words or combination of the key words "herd management," "cow management," "cow breeding," "dairy management," "dairy," "feed management," and "reproduction." Commercial systems were also reviewed.) Following Bonke et al. (2018), we chose to ask about functions of an app rather than about specific apps to avoid potential bias, because specific apps might not be known to all respondents. Farmers were asked about their herd management app use

Table 1. Statements and related constructs ${ }^{1}$

\begin{tabular}{|c|c|c|}
\hline Construct & Indicator & Statement \\
\hline ITU & itu2 & It is possible that I would use herd management smartphone apps in the near future. \\
\hline \multirow{2}{*}{ PEOU } & peou3 & I think I would find it easy to acquire the necessary skills to use herd management smartphone apps. \\
\hline & peou4 & I think that I could easily learn how to use herd management smartphone apps. \\
\hline \multirow[t]{3}{*}{$\mathrm{PU}$} & pu1 & $\begin{array}{l}\text { In general, herd management smartphone apps would be useful to improve the overall effectiveness of my } \\
\text { herd management. }\end{array}$ \\
\hline & pu3 & $\begin{array}{l}\text { Use of herd management smartphone apps would improve my herd management in terms of cost } \\
\text { effectiveness. }\end{array}$ \\
\hline & pu4 & $\begin{array}{l}\text { Use of herd management smartphone apps would facilitate the observation of animal welfare and health in } \\
\text { my herd. }\end{array}$ \\
\hline
\end{tabular}

${ }^{1}$ ITU $=$ intention to use; PEOU $=$ perceived ease of use; PU = perceived usefulness. Statements were translated from German into English and were presented in randomized order; the wording was based on the works of Davis (1989) and Venkatesh and Davis (2000). 
frequency $(1=$ never, $2=$ less than once a week, $3=$ weekly, $4=$ more than once a week, $5=$ daily, $6=$ more than once a day). Multiple answers were not allowed. This frequency scale was also used by Kittinger et al. (2012) for the use of digital technologies. Last, dairy farmers were asked to provide socio-demographic and farm-related information. After removal of incomplete surveys (not all answers given), the final sample included in the analysis consisted of 280 dairy farmers.

\section{Statistical Testing}

Farmers were asked to rate the usefulness of the presented herd management app functions in supporting their herd management. To check for differences in the usefulness scores for several topics between users and nonusers of herd management smartphone apps, we applied a Mann-Whitney $U$-test. A Mann-Whitney $U$-test is a nonparametric test applied if non-normality in the data occurs.

\section{Estimation Techniques}

Structural equation modeling was used to estimate the TAM because this allowed for the simultaneous estimations of the relationships between constructs as well as between indicators and constructs (Bagozzi and Phillips, 1982). Specifically, we applied partial least squares (PLS) structural equation modeling, because this approach is less restrictive concerning the structure of the data than covariance-based structural equation modeling, which requires normally distributed data. Furthermore, PLS structural equation modeling allows for the use of constructs with only 1 or 2 items (Hair et al., 2011). Both reasons apply for our proposed model.

The PLS structural equation modeling aims to maximize the explained variance of the endogenous variables. The model consists of 2 parts: the outer (relationship between indicator and construct) and the inner model (causal relationship between constructs). Furthermore, outer models can be differentiated into reflective and formative outer models. In reflective models, the indicators are caused by a construct, whereas in formative models the construct is caused by the indicators (Henseler et al., 2009). All indicators in the TAM are reflective indicators (Venkatesh and Bala, 2008); we therefore applied ITU, PEOU, and PU as reflective constructs. In our applied model, HerdSize, MilkYield, Age, KnowApps, and Education are the exogenous variables and also reflective, because single items are always defined as reflective (Hair et al., 2017).

The interpretation of PLS structural equation modeling results follows 2 steps. In the first step, the outer model is evaluated, and in the second step, the inner model is assessed (Chin, 1998). For the assessment of the outer model of the estimated TAM, indicator reliability, internal consistency reliability, convergent validity, and discriminant validity are tested. Indicator reliability refers to the extent to which a construct explains each indicator's variance. The associated cutoff level for the standardized loadings is $>0.7$ (Chin, 1998). Internal consistency reliability refers to the extent to which the indicators measure the same construct (Henson, 2001). In our case, internal consistency reliability was approved by the estimation of Cronbach's $\alpha$, Dillon-Goldstein's $\rho_{c}$, and DijkstraHenseler's $\rho_{\mathrm{a}}$. The associated cut-off level for all 3 criteria is $>0.7$ (Dijkstra and Henseler, 2015; Hair et al., 2017). Convergent validity can be assumed if the average variance extracted is above the threshold of 0.5 (Hair et al., 2017). The average variance extracted describes to what extent the model captures variance from its indicators compared with the amount of variance captured due to measurement errors. Discriminant validity refers to the extent to which the constructs are separable from other constructs. In our study, discriminant validity is established by the HeterotraitMontotrait criterion. The Heterotrait-Montotrait value should be below 0.9 (Hair et al., 2017).

For the evaluation of the inner model, explained variance $\left(\mathrm{R}^{2}\right)$ and the out-of-sample predictive relevance (Stone-Geisser criterion $Q^{2}$; Geisser, 1974; Stone, 1974) are estimated. The $\mathrm{Q}^{2}$ is estimated by using blindfolding. Because no assumption about the distribution of the data is needed for PLS structural equation modeling, results for hypothesis testing of the path coefficients of the inner model are derived from a resample bootstrapping procedure. We applied 5,000 subsamples, which are required to generate values to allow for hypothesis testing following Hair et al. (2014). Data analysis for the proposed TAM was carried out using SmartPLS 3.2.7 (Ringle et al., 2015).

Following Mutyasira et al. (2018), we tested the direct effects of further exogenous variables on the endogenous variable (frequency) by using an ordered logit model. The ordered logit model is based on maximum likelihood estimation and was calculated using Stata software version 14 (Stata Corp., College Station, TX). Our proposed TAM, its extensions for herd management smartphone app adoption, and applied methodologies are graphically displayed in Figure 1.

\section{RESULTS AND DISCUSSION}

\section{Descriptive Statistics}

The descriptive statistics are given in Table 2. The dairy farmers in our sample are comparatively younger 
Table 2. Summary statistics $(\mathrm{n}=280)$

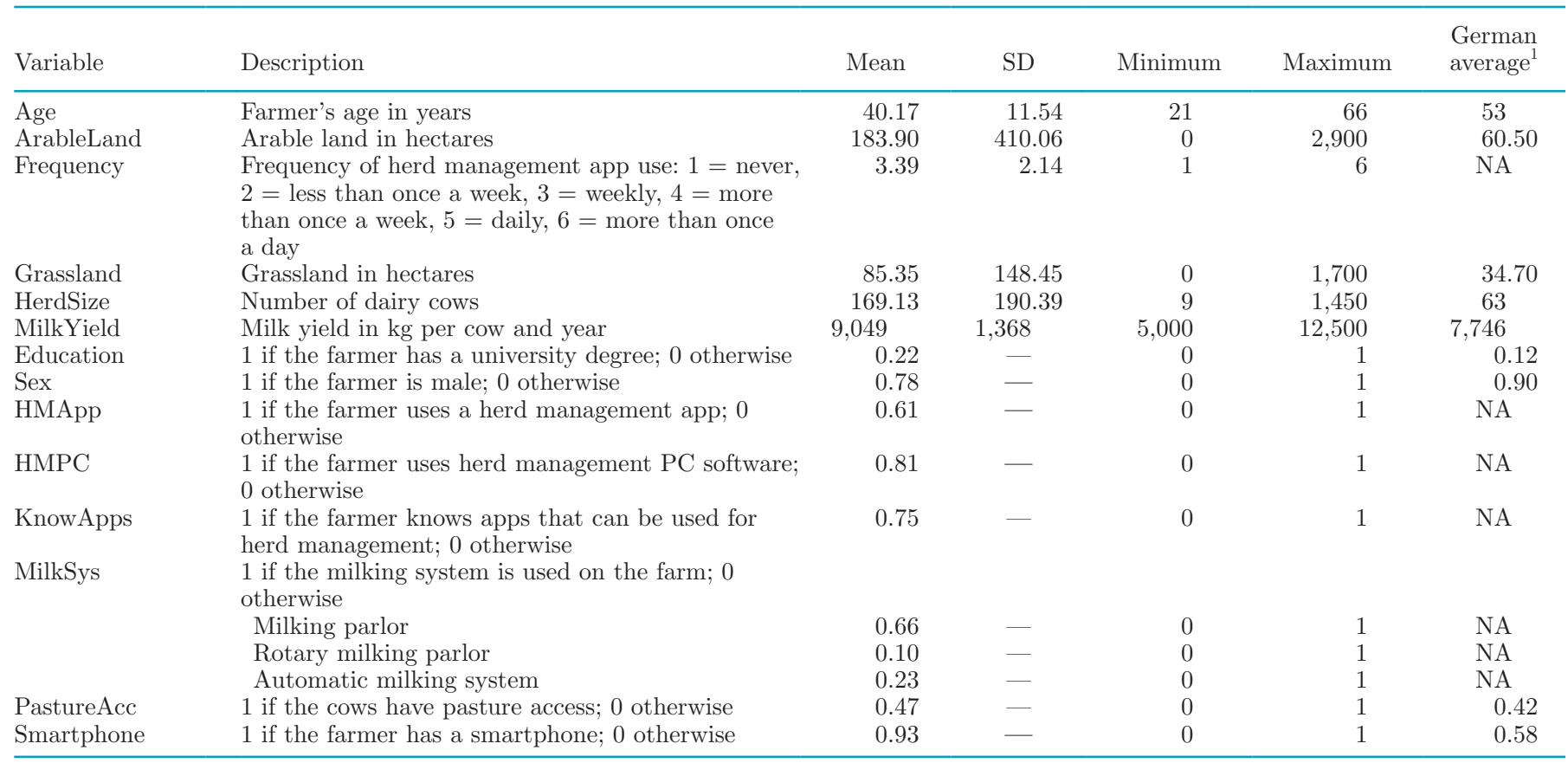

${ }^{1}$ Sources: Kleffmann Group (2016); DBV (2018); Federal Office for Agriculture and Food (2019). NA = not available.

and more educated than the German average. Bonke et al. (2018) noted that regarding the future development of DST, such as smartphones and associated apps, it is worthwhile to focus on adoption by younger farmers, because they are most likely to be the long-time users (Rose et al., 2016). Furthermore, "young farmers believe that animal welfare is essential to ensure economic profitability and sustainability" (CEJA, 2017, page 2), which is partly affected by herd management and can be achieved with modern, innovative production techniques such as smartphone herd management apps. This indicates that our sample of younger, well-educated dairy farmers, who are familiar with digital technologies, is an appropriate basis for our investigation. Our results also have to be interpreted with respect to larger herd size and higher milk yield compared with the German average. However, larger farms are most likely to be the first adopters of new innovative technologies (Tamirat et al., 2018), which should also be taken into consideration here.

With respect to herd management smartphone apps, $75 \%$ of the dairy farmers know about smartphone apps that can be used for herd management purposes. Sixtyone percent of the dairy farmers already use a herd

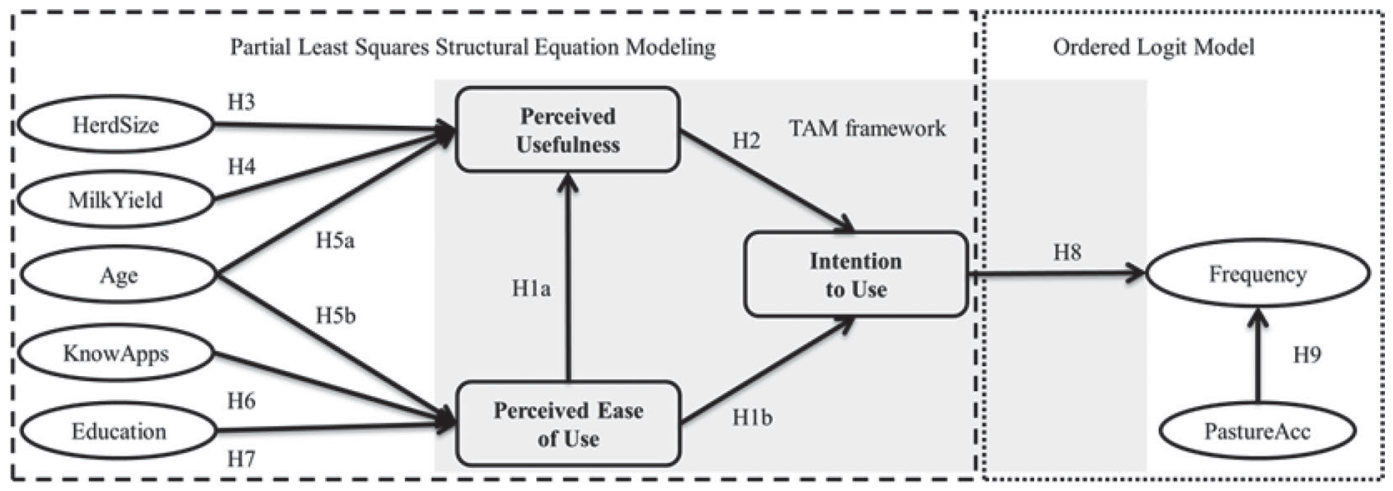

Figure 1. Image of the proposed models and applied estimation techniques. Education = whether the farmer has a university degree; HerdSize $=$ number of dairy cows; MilkYield $=$ kilograms per cow per year; Age $=$ farmer's age in years; KnowApps $=$ whether the farmer knows apps that can be used for herd management; PastureAcc = pasture access; $\mathrm{H}=$ hypothesis; TAM = technology acceptance model. 
Table 3. Frequency of herd management app use $(\mathrm{n}=280)^{1}$

\begin{tabular}{|c|c|c|c|c|c|c|}
\hline Frequency & Never & $\begin{array}{c}\text { Less than } \\
\text { once a week }\end{array}$ & Weekly & $\begin{array}{c}\text { More than } \\
\text { once a week }\end{array}$ & Daily & $\begin{array}{l}\text { More than } \\
\text { once a day }\end{array}$ \\
\hline Percentage & $38.57^{2}$ & 3.57 & 6.07 & 13.93 & 8.21 & 29.64 \\
\hline Absolute & $108^{2}$ & 10 & 17 & 39 & 23 & 83 \\
\hline
\end{tabular}

management smartphone app. Hence, not all dairy farmers who are aware of herd management smartphone apps also use them. The distribution of herd management app use across 6 frequency categories is presented in Table 3. Thirty-eight percent of the sample uses a herd management app at least once a day ( $8.21 \%$ daily; $29.64 \%$ more than once daily).

According to Mann-Whitney $U$ tests, the usefulness scores in Table 4 for data gathering, reproduction management, and animal health functions were statistically significantly greater for dairy farmers already using a herd management app compared with those who were not. One possible explanation could be that dairy farmers who are already using an app with these functions may see the benefit with respect to their herd management, as also pointed out by Borchers and Bewley (2015) for the adoption and use of precision dairy technologies. Furthermore, these functions may benefit the most from the mobility of the smartphones. Farmers can retrieve information, for instance on of cows' abnormal behavior, from anywhere and at any time with their smartphones.

No statistically significant difference was found for functions with respect to feed management and milking control, and these functions received the lowest usefulness scores. App functions with respect to indoor feed management may not benefit from the mobile character of smartphones. Furthermore, feed ratio calculation and feeding may already be automated. Thus, herd management smartphone apps may not contribute to the facilitation or optimization of feed management to a great extent. Milking control may already be established with computer systems that call the landline telephone of the dairy farmer in case of emergency. It is plausible that a specific smartphone app with that function might not be necessary or is not suited to work with already implemented milking control systems. The usefulness scores of this function were ranked the same for user and nonuser. Both groups display the same needs with respect to decision support in their working routine.

With respect to grazing systems, cow health and, more specifically, cow fertility are important factors for system efficiency (Shalloo et al., 2018), which can also be supported by herd management smartphone apps. The ranking of the usefulness scores in Table 4 reflects the needs for cow health and fertility management in pasture-based dairy systems. Shalloo et al. (2014) noted that cow fertility is considered more important in seasonal dairy production such as in pasture-based systems. Herd management smartphone apps assisting dairy farmers in their reproduction management can

Table 4. Usefulness scores of several herd management app functions, comparing farmers using and not using a herd management smartphone app (HMApp; $\mathrm{n}=280$ )

\begin{tabular}{|c|c|c|c|c|}
\hline \multirow[b]{2}{*}{ Function } & \multicolumn{4}{|c|}{ Mean usefulness scores ${ }^{1}$} \\
\hline & Using $^{2}$ & $\begin{array}{l}\text { Not } \\
\text { using }^{2}\end{array}$ & Difference & Test \\
\hline $\begin{array}{l}\text { Reproduction management (e.g., bull selection, timing of drying } \\
\text { off cows) }\end{array}$ & 4.26 & 3.70 & 0.56 & Mann-Whitney $U^{* * *}$ \\
\hline $\begin{array}{l}\text { Animal health (e.g., animal positioning and monitoring of lying } \\
\text { and feeding behavior) }\end{array}$ & 4.04 & 3.66 & 0.38 & Mann-Whitney $U^{* *}$ \\
\hline Milking control (e.g., control of tanks, control of milking technique) & 3.70 & 3.56 & 0.14 & Mann-Whitney $U$ \\
\hline Feed management (e.g., calculation of feed ratios) & 3.07 & 2.92 & 0.15 & Mann-Whitney $U$ \\
\hline
\end{tabular}

${ }^{1}$ Likert scale: 1 = not useful at all, $5=$ very useful.

${ }^{2}$ Specification according to the dummy variable HMApp $=1(\mathrm{n}=172)$ and HMApp $=0(\mathrm{n}=108)$.

${ }^{*} P<0.05,{ }^{* *} P<0.01,{ }^{* * *} P<0.001$. 
Table 5. Evaluation of the outer model $(\mathrm{n}=280)^{1}$

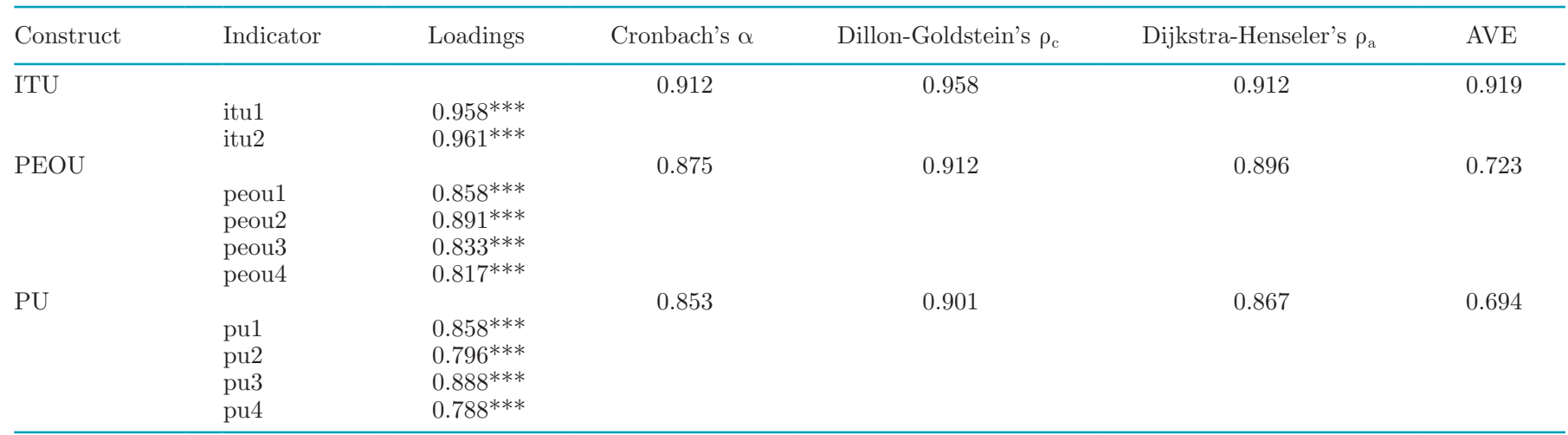

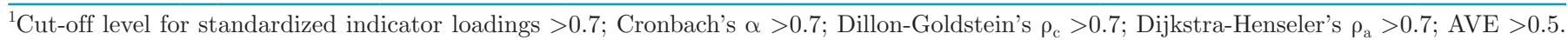
$\mathrm{AVE}=$ average variance extracted; ITU $=$ intention to use; $\mathrm{PEOU}=$ perceived ease of use; $\mathrm{PU}=$ perceived usefulness.

$* * * P<0.001$.

also contribute effectively to the herd management efficiency in pasture-based systems. Observing the movement, lameness, lying, and feeding behavior is also of great importance for the herd management of grazing cows (Delagarde and Lamberton, 2015). However, obstacles in use due to connectivity problems could arise in using sensor technologies (Shalloo et al., 2018), which can be connected to smartphones. Commercial systems like, for example, smaXtex (smaXtex, 2019) provide a solution as synchronization of data occurs if the cow enters the barn or comes close to a repeater. Still, this less frequent update of information of cow behavior could assist dairy farmers in their herd management in grazing systems.

\section{Evaluation of the Outer Model}

For the assessment of the outer model of the estimated TAM, indicator reliability, internal consistency reliability, convergent validity, and discriminant validity were tested. The results are given in Tables 5 and 6 . The lowest standardized loading shows a value of 0.788 (indicator pu4-use of herd management smartphone apps would facilitate the observation of animal welfare and health in my herd), which is above the associated cut-off level of $>0.7$ (Chin, 1998). Internal consistency reliability is approved by the estimation of Cronbach's $\alpha$, Dillon-Goldstein's $\rho_{c}$, and Dijkstra-Henseler's $\rho_{a}$. The associated cut-off level for all 3 criteria is $>0.7$ (Dijkstra and Henseler, 2015; Hair et al., 2017), which all of our estimates exceed. Therefore, internal consistency of our model is given. In our model, the lowest average variance extracted was 0.694 for PU, satisfying convergent validity. Discriminant validity is established by the Heterotrait-Montotrait ratios, which were below the benchmark of 0.9 (Hair et al., 2017) in our model (Table 6).

\section{Evaluation of the Inner Model}

The results of the inner model validation are given in Table 7. (Multicollinearity was tested. The calculation of variance inflation factors did not exceed the critical value of 5 for all variables, which indicates the absence of issues with multicollinearity; Hair et al., 2017). Our model explains $63 \%$ of the variance in the intention

Table 6. Discriminant validity: Heterotrait-Monotrait ratios $(\mathrm{n}=280)^{1}$

\begin{tabular}{|c|c|c|c|c|c|c|c|c|}
\hline Variable & Education & HerdSize & ITU & MilkYield & PEOU & $\mathrm{PU}$ & Age & KnowApps \\
\hline HerdSize & 0.216 & & & & & & & \\
\hline ITU & 0.095 & 0.050 & & & & & & \\
\hline PEOU & 0.200 & 0.082 & 0.720 & 0.100 & & & & \\
\hline $\mathrm{PU}$ & 0.062 & 0.039 & 0.841 & 0.220 & 0.657 & & & \\
\hline Age & 0.073 & 0.016 & 0.071 & 0.006 & 0.136 & 0.076 & & \\
\hline KnowApps & 0.114 & 0.042 & 0.438 & 0.019 & 0.417 & 0.349 & 0.105 & \\
\hline
\end{tabular}

${ }^{1}$ The cut-off level for the Heterotrait-Monotrait criterion is $<0.9$. Education $=$ whether the farmer has a university degree; HerdSize $=$ number of dairy cows; ITU = intention to use; MilkYield = kilograms per cow per year; PEOU = perceived ease of use; PU = perceived usefulness; Age $=$ farmer's age in years; KnowApps $=$ whether the farmer knows apps that can be used for herd management. 
Table 7. Explained variance and predictive relevance of the technology acceptance model $(\mathrm{n}=280)^{1}$

\begin{tabular}{lcc}
\hline Construct & $\mathrm{R}^{2}$ & $\mathrm{Q}^{2}$ \\
\hline ITU & 0.63 & 0.54 \\
PEOU & 0.38 & 0.12 \\
PU & 0.18 & 0.24
\end{tabular}

${ }^{1}$ Cut-off level for $\mathrm{R}^{2}>0.1, \mathrm{Q}^{2}>0$. ITU $=$ intention to use; $\mathrm{PEOU}=$ perceived ease of use; $\mathrm{PU}=$ perceived usefulness.

to use herd management smartphone apps. This value can be described as substantial (Cohen, 1988). Furthermore, explained variance in the constructs PEOU and PU amount to $38 \%$ and $18 \%$, which can be classified as substantial and moderate, respectively (Cohen, 1988). To evaluate the out-of-sample predictive power of our model, the Stoner-Geisser Q ${ }^{2}$ (Geisser, 1974; Stone, 1974) was calculated using the blindfolding procedure with an omission distance of 6 . The $\mathrm{Q}^{2}$ for all constructs was above zero, indicating that the model had a good predictive relevance (Hair et al., 2017). The highest $Q^{2}$ was estimated for the construct ITU with a coefficient of 0.54 , followed by the coefficients of $\mathrm{Q}^{2}$ for the constructs PU (0.24) and PEOU (0.12).

\section{Discussion of the Inner and Ordered Logit Model Results}

The upper part of Table 8 shows the tested hypotheses and path coefficients. The $t$-statistics for each path coefficient are estimated by bootstrapping with 5,000 subsamples. The path coefficients can be interpreted as standardized $\beta$ coefficients (Hair et al., 2017). The path coefficient for PEOU $\rightarrow \mathrm{PU}$ had the expected positive sign and was statistically significant. Therefore, H1a is supported by our model; if a dairy farmer perceives use of herd management smartphone apps as easy, he or she perceives such an app as more useful. Dairy farmers who perceive handling an app as easy may benefit more from the various functions. Our results support $\mathrm{H} 1 \mathrm{~b}$ as well, because the path coefficient for PEOU $\rightarrow$ ITU was statistically significant and had the expected positive sign. Thus, a perceived effortless handling of a herd management smartphone app increases a dairy farmer's intention to use such an app.

Hypothesis H2 analyzes the effect of PU on ITU. The path coefficient for $\mathrm{PU} \rightarrow$ ITU was statistically significant and had the expected positive sign. It can be concluded that if a dairy farmer perceives the function provided by herd management smartphone apps as useful for his or her operational activities, he or she has a higher intention to use such apps. Therefore, developers and providers should highlight the benefits of using herd management smartphone apps.

The path coefficient for HerdSize $\rightarrow$ PU did not have the expected sign and was not statistically significant; therefore, H3 is not supported. The missing statistical significance of the effect can be explained by the fact that regardless of herd size, observing and collecting individual animal data is important for effective herd management. Thus, adoption of herd management smartphone apps is attractive for dairy farmers of all

Table 8. Results of hypothesis testing $(\mathrm{n}=280)^{1}$

\begin{tabular}{|c|c|c|c|c|c|c|}
\hline Item & Hypothesis & $\begin{array}{l}\text { Path } \\
\text { coefficients }\end{array}$ & $\begin{array}{c}\text { t-statistic } \\
(\text { bootstrap results) }\end{array}$ & $\begin{array}{l}\text { Odds } \\
\text { ratio }\end{array}$ & SE & $\begin{array}{l}\text { Supported } \\
\text { hypothesis? }\end{array}$ \\
\hline \multicolumn{7}{|c|}{ PLS $^{3}$ structural equation model } \\
\hline $\mathrm{PEOU} \rightarrow \mathrm{PU}$ & H1a & $0.590 * * *$ & 14.369 & & & Supported \\
\hline $\mathrm{PU} \rightarrow \mathrm{ITU}$ & $\mathrm{H} 2$ & $0.547^{* * *}$ & 10.377 & & & Supported \\
\hline HerdSize $\rightarrow$ PU & H3 & -0.068 & 1.312 & & & Not supported \\
\hline MilkYield $\rightarrow$ PU & H4 & $0.166^{* *}$ & 3.294 & & & Supported \\
\hline KnowApps $\rightarrow$ PEOU & $\mathrm{H} 6$ & $0.381^{* * *}$ & 7.014 & & & Supported \\
\hline Education $\rightarrow$ PEOU & $\mathrm{H} 7$ & $0.135^{*}$ & 2.577 & & & Supported \\
\hline \multicolumn{7}{|l|}{ Ordered logit model ${ }^{4}$} \\
\hline ITU $\rightarrow$ Frequency & $\mathrm{H} 8$ & & & $3.819^{* * *}$ & 0.569 & Supported \\
\hline PastureAcc $\rightarrow$ Frequency & H9 & & & 0.840 & 0.196 & Not supported \\
\hline
\end{tabular}

${ }^{1} \mathrm{PEOU}=$ perceived ease of use; $\mathrm{PU}=$ perceived usefulness; ITU = intention to use; HerdSize = number of dairy cows; MilkYield $=$ kilograms per cow per year; Age = farmer's age in years; KnowApps = whether the farmer knows apps that can be used for herd management; Education $=$ whether the farmer has a university degree; Frequency $=$ frequency of herd management app use; PastureAcc = whether the cows have pasture access.

${ }^{2} 5,000$ subsamples applied.

${ }^{3} \mathrm{PLS}=$ partial least squares.

${ }^{4}$ Nagelkerke $\mathrm{R}^{2}=0.336$, Cox-Snell $\mathrm{R}^{2}=0.320$, likelihood ratio $\chi^{2}(2)=107.81^{* * *}$, Brant test $\left(\chi^{2}=13.28\right)$, log-likelihood $=-365.21$.

${ }^{* * *} P<0.001 ;{ }^{* *} P<0.01 ;{ }^{*} P<0.05$. 
scales, which should be recognized by developers and providers.

Hypothesis $\mathrm{H} 4$ addresses the effect of milk yield on PU. The path coefficient for MilkYield $\rightarrow$ PU had the expected positive sign and was statistically significant. A high milk yield implies that a farmer has already established a well-functioning herd management system. With the help of herd management smartphone apps, he or she can adjust more easily to small changes and therefore maintain or even increase the high milk yield. Inferior milk yields imply that comprehensive changes in herd management should be considered, which cannot solely be solved and assisted by using herd management smartphone apps.

The path coefficient for Age $\rightarrow \mathrm{PU}$ did not have the expected sign and was not statistically significant, indicating that the farmer's age has no statistically significant effect on perceived usefulness. Hence, H5a was not supported. Although older dairy farmers may have more experience with respect to herd management, using an app can still provide information faster and in a comprehensive manner; thus, older dairy farmers also perceive these functions as useful. In particular, the observation of moving and lying behavior can be enabled by apps and can consequently facilitate animal observation for dairy farmers of all ages. With respect to $\mathrm{H} 5 \mathrm{~b}$, the path coefficient for Age $\rightarrow$ PEOU had the expected sign but was not statistically significant. Because younger farmers are more experienced with digital technologies (Rose et al., 2016), a statistically significant effect was expected. Most of the dairy farmers in our sample have a smartphone (Table 1) and can thus be described as being familiar, at least on a basic level, with smartphone technology. This could explain why the age of the farmers does not have a statistically significant effect.

Hypothesis $\mathrm{H} 6$ analyzes the effect of the knowledge of herd management apps on PEOU. The path coefficient for KnowApps $\rightarrow$ PEOU had the expected positive sign and was statistically significant. This result is reasonable because knowledge about specific herd management apps implies that farmers can better evaluate the function of an app and therefore perceive the use of such an app as easier (Bonke et al., 2018).

Hypothesis $\mathrm{H} 7$ describes the effect of dairy farmers' education on the PEOU. The path coefficient for Education $\rightarrow$ PEOU had the expected positive sign and was statistically significant. A higher level of education therefore facilitates the use and adoption of herd management smartphone apps, because education enables a farmer to process information regarding new technologies more easily (Poolsawas and Napasintuwong, 2013). Dairy farmers who hold a university degree may have had more experience with digital technologies from their time at university and thus perceive operating herd management apps as easier. Additionally, Bramley und Ouzman (2018) showed that digital literacy could facilitate adoption of precision agriculture technologies. Thus, schooling for farmers in digitalization could also facilitate the adoption of such apps. Farmers also show a high interest in digitalization training courses (Michels et al., 2019). With respect to PEOU, Borghi et al. (2016) reasoned that precision agricultural technologies should be kept simple in use, which also holds true for the development and use of herd management smartphone apps according to our results.

The results of the ordered logit model are given in the lower part of Table 8. A likelihood ratio test was statistically significant [likelihood ratio $\chi^{2}(2)=107.81$ ], indicating that at least one coefficient is statistically significantly different from zero. The log-likelihood value was -365.21 . Nagelkerke $\mathrm{R}^{2}$ and Cox-Snell $\mathrm{R}^{2}$ amount to 0.336 and 0.320 , respectively. The proportional odds assumption (i.e., the assumption that the $\beta$ coefficients are equal across all ordinal stages) is tested via a Brant test $\left(\chi^{2}=13.28\right)$, which was not statistically significant. The selected model provides odds ratios. The odds ratios close to one suggest little probability change with respect to the frequency. Our model supports H8. The expected effect of ITU on frequency is proven to be statistically significant with odds greater than one (i.e., higher intention to use herd management apps leads to more frequent use of herd management apps). Thus, all hypotheses of the original TAM were supported, which completes one of our research goals.

Last, the effect of cows' pasture access on the frequency of smartphone app use was addressed with H9. The odds ratio below one indicates that farmers with grazing systems are less frequent users. However, H9 was not supported because the odds ratio was not statistically significant. As discussed for the results in Table 4, several herd management smartphone apps can also be used in grazing systems. However, some particular apps in connection with sensor technologies are expected to be used less frequently due to connectivity problems that inhibit constant update of data (Shalloo et al., 2018). Another aspect that could explain the missing statistically significant effect might be that other kinds of smartphone apps are used more frequently in grazing systems than in indoor systems. Grassland as a primary resource of feed required real-time measurement of herbage mass and quality. This information is required to optimize grazing timing and nutrition management. Dairy farmers with grazing systems could therefore make use of smartphone apps with respect to pasture management, especially since alternatives, 
such as sensor technologies for pasture management, are still in development and, with a few exceptions, not commercially available (Shalloo et al., 2018). Available smartphone apps can assist dairy farmers in grazing-related calculations, for instance, the carrying capacity and stocking rates. Forage budgeting tools can help maintain a productive balance between stock and pasture available. Furthermore, daily rotation and paddock selection plans can be generated, stored, and also shared with employees. Likewise, record keeping, recall, and assessment of cow or group data in grazing systems can assist dairy farmers in detecting problems faster and making corrections sooner. Hence, differences in frequency could not be determined because grazing system farmers have different needs and therefore demand different smartphone apps.

\section{Limitations}

We did not ask for reasons why farmers do not use herd management smartphone apps, which could have been interesting for developers and providers, because not all dairy farmers in our sample who know about herd management apps also use them. This study did not differentiate explicitly between grazing and indoor systems. Therefore, use, obstacles in practice, and perceived usefulness of different herd management smartphone apps in grazing and indoor systems could be captured in more detail and compared in future studies because "implementing technology in grass-based dairying brings unique opportunities and challenges" (Shalloo et al., 2018, page 262). Adoption patterns of smartphone apps supporting pasture management could also be an interesting focus for further research because they were not considered in this study.

\section{CONCLUSIONS}

This study provides a greater understanding of the adoption and use of herd management smartphone apps by German dairy farmers. We also assessed which herd management app functions are perceived as most useful. More than 38\% of the dairy farmers used herd management smartphone apps on a daily basis, whereas $39 \%$ did not use any herd management smartphone app. Animal health observation, reproduction management, and data gathering functions are perceived as very useful by German dairy farmers. Developers and providers should focus on these functions for future development. Because not all dairy farmers who are aware of herd management smartphone apps are also users of such apps, large potential exists to increase the adoption and use of smartphones and related apps in dairy herd management through effective marketing and advertising for which the results of this study can be used. This study shows that the assumptions of the TAM hold true for the intention to adopt and the actual use of herd management smartphone apps in dairy farming. Key attitudinal beliefs about the perceived ease of use and the perceived usefulness are major determinants of the intention to use, which in turn strongly influences the actual use of herd management smartphone apps. Consequently, benefits of use should be clearly visible for farmers to promote more widespread adoption. In line with that, handling of an app and provision of information should be kept as simple as possible to make herd management smartphone apps attractive for farmers regardless of educational background and previous knowledge. The results also imply that herd management smartphone apps are perceived as useful by dairy farmers with herds of all sizes, which should also be considered by developers and providers. Furthermore, herd management smartphone app use was discussed in the context of grazing systems. Having grazing practices in place did not significantly affect the use frequency of apps in our study. However, the applicability of herd management smartphone app functions associated with sensor technologies might be limited for grazing practices currently. Grazing systems require additional app functions that were not explicitly part of this study. Future research could therefore assess specific functions that are useful for grazing systems. Furthermore, the evaluation of willingness to pay for herd management smartphone apps could be an interesting research topic because the assessment of the financial value of a DST is an important part of the adoption process.

\section{REFERENCES}

Abdelsayed, M. 2017. Health data for healthy cows. Aust. Holstein J. Apr/May:28-29.

Bagozzi, R. P., and L. W. Phillips. 1982. Representing and testing organizational theories: A holistic construal. Adm. Sci. Q. 27:459489. https://doi.org/10.2307/2392322.

Barragan, A. A., J. D. Workman, S. Bas, K. L. Proudfoot, and G. M. Schuenemann. 2016. Assessment of an application for touchscreen devices to record calving-related events in dairy herds and monitor personnel performance. J. Dairy Sci. 99:5662-5670. https://doi .org/10.3168/jds.2015-10841.

Bonke, V., W. Fecke, M. Michels, and O. Musshoff. 2018. Willingness to pay for smartphone apps facilitating sustainable crop protection. Agron. Sustain. Dev. 38:1-10. https://doi.org/10.1007/ s13593-018-0532-4.

Borchers, M. R. 2015. An evaluation of precision dairy farming technology adoption, perception, effectiveness, and use. MS Thesis. Univ. Kentucky, Lexington. Accessed Apr. 26, 2019. https:// uknowledge.uky.edu/animalsci_etds/45.

Borchers, M. R., and J. M. Bewley. 2015. An assessment of producer precision dairy farming technology use, prepurchase considerations, and usefulness. J. Dairy Sci. 98:4198-4205. https://doi .org/10.3168/jds.2014-8963. 
Borghi, E., J. C. Avanzi, L. Bortolon, A. L. Junior, and E. S. O. Bortolon. 2016. Adoption and use of precision agriculture in Brazil: Perception of growers and service dealership. J. Agric. Sci. 8:89-104. https://doi.org/10.5539/jas.v8n11p89.

Bramley, R. G. V., and J. Ouzman. 2018. Farmer attitudes to the use of sensors and automation in fertilizer decision-making: Nitrogen fertilization in the Australian grains sector. Precis. Agric. 20:157175. https://doi.org/10.1007/s11119-018-9589-y.

Calsamiglia, S., S. Astiz, J. Baucells, and L. Castillejos. 2018. A stochastic dynamic model of a dairy farm to evaluate the technical and economic performance under different scenarios. J. Dairy Sci. 101:7517-7530. https://doi.org/10.3168/jds.2017-12980.

Carrer, M. J., H. M. de Souza Filho, and M. O. Batalha. 2017. Factors influencing the adoption of Farm Management Information Systems (FMIS) by Brazilian citrus farmers. Comput. Electron. Agric. 138:11-19. https://doi.org/10.1016/j.compag.2017.04.004.

CEJA. 2017. European young farmers: Building a sustainable sector. Accessed Oct. 2, 2018. http://www.ceja.eu/wp-content/uploads/ 2017/09/CEJA-DeLaval-Survey-European-Young-Farmers.pdf.

Chin, W. W. 1998. The partial least squares approach to structural equation modeling. Pages 295-336 in Modern Methods for Business Research. G. A. Marcoulides, ed. Psychology Press, Taylor and Francis Group, New York, NY.

Cohen, J. 1988. Statistical Power Analysis for the Behavioral Sciences. 2nd ed. Acad. Press, New York, NY.

Davis, F. D. 1989. Perceived usefulness, perceived ease of use, and user acceptance of information technology. Manage. Inf. Syst. Q. 13:319-340. https://doi.org/10.2307/249008.

DBV (Deutscher Bauernverband). 2018. Situationsbericht 2017/18. German Famers Federation. Accessed Jul. 2, 2018. http://www .bauernverband.de/situationsbericht-2017-18.

Debauche, O., S. Mahmoudi, A. L. H. Andriamandroso, P. Manneback, J. Bindelle, and F. Lebeau. 2018. Cloud services integration for farm animals' behavior studies based on smartphones as activity sensors. J. Ambient Intell. Humaniz. Comput. 1-12. https:// doi.org/10.1007/s12652-018-0845-9.

Delagarde, R., and P. Lamberton. 2015. Daily grazing time of dairy cows is recorded accurately using the Lifecorder Plus device. Appl. Anim. Behav. Sci. 165:25-32. https://doi.org/10.1016/j.applanim .2015.01.014.

Dijkstra, T. K., and J. Henseler. 2015. Consistent partial least squares path modeling. Manage. Inf. Syst. Q. 39:297-316. https://doi.org/ 10.25300/MISQ/2015/39.2.02

Evans, K. J., A. Terhorst, and B. H. Hang. 2017. From data to decisions: Helping crop producers build their actionable knowledge. Crit. Rev. Plant Sci. 36:71-88. https://doi.org/10.1080/07352689 .2017.1336047.

Federal Office for Agriculture and Food. 2019. Dairy Farming in Germany. Accessed Apr. 2, 2019. https://www.praxis-agrar.de/tier/ rinder/milchviehhaltung-in-deutschland/.

Fishbein, M., and I. Ajzen. 1975. Belief, Attitude, Intention and Behavior: An Introduction to Theory and Research. Addison-Wesly, Reading, MA.

Gargiulo, J. I., C. R. Eastwood, S. C. Garcia, and N. A. Lyons. 2018. Dairy farmers with larger herd sizes adopt more precision dairy technologies. J. Dairy Sci. 101:5466-5473. https://doi.org/10 .3168/jds.2017-13324.

Geisser, S. 1974. A predictive approach to the random effect model. Biometrika 61:101-107. https://doi.org/10.2307/2334290.

Gerpott, T. J., S. Thomas, and M. Weichert. 2013. Personal characteristics and mobile Internet use intensity of consumers with computer-centric communication devices: An exploratory empirical study of iPad and laptop users in Germany. Telemat. Inform. 30:87-99. https://doi.org/10.1016/j.tele.2012.03.008.

Glenna, L. L., R. A. Jussaume, and J. C. Dawson. 2011. How farmers matter in shaping agricultural technologies: Social and structural characteristics of wheat growers and wheat varieties. Agric. Human Values 28:213-224. https://doi.org/10.1007/s10460-010-9275 -9 .
Hair, J. F., G. T. M. Hult, C. M. Ringle, and M. Sarstedt. 2017. A Primer on Partial Least Squares Structural Equation Modeling (PLS-SEM). 2nd ed. Sage Publ., Thousand Oaks, CA.

Hair, J. F., C. M. Ringle, and M. Sarstedt. 2011. PLS-SEM: Indeed a silver bullet. J. Mark. Theory Pract. 19:139-152. https://doi.org/ 10.2753/MTP1069-6679190202.

Hair, J. F., M. Sarstedt, L. Hopkins, and G. V. Kuppelwieser. 2014. Partial least squares structural equation modeling (PLS-SEM): An emerging tool in business research. Eur. Bus. Rev. 26:106-121. https://doi.org/10.1108/EBR-10-2013-0128.

Henseler, J., C. M. Ringle, and R. R. Sinkovics. 2009. The use of partial least squares path modeling in international marketing. Pages 277-319 in New Challenges to International Marketing. R. R. Sinkovics and P. N. Ghauri, ed. Emerald Group Publ. Ltd., Bingley, UK.

Henson, R. K. 2001. Understanding internal consistency reliability estimates: A conceptual primer on coefficient alpha. Meas. Eval. Couns. Dev. 34:177-189.

Herd, D. 2014. Network systems and cloud applications in livestock farming. Landtechnik: Agric. Eng. 69:245-248. https://doi.org/10 $.15150 / 1 t .2014 .617$.

Kamilaris, A., and A. Pitsillides. 2016. Mobile phone computing and the internet of things: A survey. IEEE Internet Things J 3:885898. https://doi.org/10.1109/JIOT.2016.2600569.

Kittinger, R., C. J. Correia, and J. G. Irons. 2012. Relationship between Facebook use and problematic Internet use among college students. Cyberpsychol. Behav. Soc. Netw. 15:324-327. https://doi .org/10.1089/cyber.2010.0410.

Kleffmann Group. 2016. New media tracker: $75 \%$ of German farmers are online daily - More than one might expect. Accessed Jun. 25,2018 . https://www.kleffmann.com/en/information-center/ information-center/new-media-tracker

Kuehne, G., R. Llewellyn, D. J. Pannell, R. Wilkinson, P. Dolling, J. Ouzman, and M. Ewing. 2017. Predicting farmer uptake of new agricultural practices: A tool for research, extension and policy. Agric. Syst. 156:115-125. https://doi.org/10.1016/j.agsy.2017.06 .007 .

Läpple, D., A. Renwick, and F. Thorne. 2015. Measuring and understanding the drivers of agricultural innovation: Evidence from Ireland. Food Policy 51:1-8. https://doi.org/10.1016/j.foodpol.2014 .11 .003 .

McDonald, R., K. Heanue, K. Pierce, and B. Horan. 2016. Factors influencing new entrant dairy farmer's decision-making process around technology adoption. J. Agric. Educ. Ext. 22:163-177. https://doi.org/10.1080/1389224X.2015.1026364.

Michels, M., W. Fecke, P. J. Weller von Ahlefeld, O. Mußhoff, A. Heckmann, and F. Beneke. 2019. Farmers' willingness to pay for digitalization training courses. Berichte über Landwirtschaft-Zeitschrift für Agrarpolitik und Landwirtschaft 97:1-18. https://doi.org/10 .12767/buel.v97i1.204.

Mills, J., P. Gaskell, J. Ingram, J. Dwyer, M. Reed, and C. Short. 2017. Engaging farmers in environmental management through a better understanding of behaviour. Agric. Human Values 34:283299. https://doi.org/10.1007/s10460-016-9705-4.

Mintert, J., D. Widmar, M. Langemeier, M. Boehlje, and B. Erickson. 2015. The challenges of precision agriculture: Is big data the answer? Pages 1-9 in Proc. South. Agric. Econ. Assoc. (SAEA) Annu. Meet., San Antonio, TX. Accessed Dec. 18, 2018. http:// ageconsearch.umn.edu//handle/230057.

Mutyasira, V., D. Hoag, and D. Pendell. 2018. The adoption of sustainable agricultural practices by smallholder farmers in Ethiopian highlands: An integrative approach. Cogent Food Agric. 4:1-17. https://doi.org/10.1080/23311932.2018.1552439.

Poolsawas, S., and O. Napasintuwong. 2013. Farmer innovativeness and hybrid maize diffusion in Thailand. J. Int. Agric. Ext. Educ. 20:51-65. https://doi.org/10.5191/jiaee.2013.202.

Ringle, C. M., S. Wende, and J.-M. Becker. 2015. SmartPLS3. Boenningsted: SmartPLS GmbH. Accessed Jun. 25, 2018. https://www .smartpls.com/. 
Rose, D. C., W. J. Sutherland, C. Parker, M. Lobley, M. Winter, C. Morris, S. Twining, C. Foulkes, T. Amano, and L. V. Dicks. 2016. Decision support tools for agriculture: Towards effective design and delivery. Agric. Syst. 149:165-174. https://doi.org/10.1016/j .agsy.2016.09.009

Schaak, H., and O. Mußhoff. 2018. Understanding the adoption of grazing practices in German dairy farming. Agric. Syst. 165:230239. https://doi.org/10.1016/j.agsy.2018.06.015.

Shalloo, L., A. Cromie, and N. McHugh. 2014. Effect of fertility on the economics of pasture-based dairy systems. Animal 8(Suppl. 1):222-231. https://doi.org/10.1017/S1751731114000615.

Shalloo, L., M. O'Donovan, L. Leso, J. Werner, E. Ruelle, A. Geoghegan, N. Delaby, and N. O'leary. 2018. Grass-based dairy systems, data and precision technologies. Animal 12(Suppl. 2):s262-271. https://doi.org/10.1017/S175173111800246X.

smaXtec. 2019. smaXtec and pasture. Accessed May 5, 2019. https:// www.smaxtec.com/en/news-stories/smaxtec-pasture/.

Stone, M. 1974. Cross-validatory choice and assessment of statistical predictions. J. R. Stat. Soc. Series B Stat. Methodol. 36:111-147.

Tamirat, T. W., S. M. Pedersen, and K. M. Lind. 2018. Farm and operator characteristics affecting adoption of precision agriculture in Denmark and Germany. Acta. Agric. Scand. B-S. P. 684349-357. https://doi.org/10.1080/09064710.2017.1402949.
Thompson, N., C. Bir, D. A. Widmar, and J. R. Mintert. 2018. Farmer perceptions of precision agriculture technology benefits. J. Agric. Appl. Econ. 51:142-163. https://doi.org/10.1017/aae.2018.27.

Vanclay, F. 2004. Social principles for agricultural extension to assist in the promotion of natural resource management. Aust. J. Exp. Agric. 44:213-222. https://doi.org/10.1071/EA02139.

Venkatesh, V., and H. Bala. 2008. Technology acceptance model 3 and a research agenda on interventions. Decis. Sci. 39:273-315. https:/ /doi.org/10.1111/j.1540-5915.2008.00192.x.

Venkatesh, V., and F. D. Davis. 2000. A theoretical extension of the technology acceptance model: Four longitudinal field studies. Manage. Sci. 46:186-204. https://doi.org/10.1287/mnsc.46.2.186 .11926 .

Verma, P., and N. Sinha. 2018. Integrating perceived economic wellbeing to technology acceptance model: The case of mobile based agricultural extension service. Technol. Forecast. Soc. Change 126:207-216. https://doi.org/10.1016/j.techfore.2017.08.013.

Werner, J., J. Viel, J. Niederhauser, N. O'Leary, C. Umstatter, and B. O'Brien. 2018. Validation of new algorithms for the RumiWatch noseband sensor to detect grazing behaviour of dairy cows. Pages 917-919 in Sustainable Meat and Milk Production from Grasslands. Proc. 27th Gen. Meet. Eur. Grassl. Fed., Cork, Ireland Anim. Grassl. Res. Innovat. Centre, Teagasc, Ireland. 